\title{
Nondialytic Therapy for Elderly Patients in a Critical Care Setting
}

\author{
Hideaki Ishikawa ${ }^{a}$ b Junichi Sakamotob \\ ${ }^{a}$ Department of Nephrology at ${ }^{b}$ Tokai Central Hospital of Japan, Mutual Aid Association \\ of Public School Teachers, Kakamigahara, Japan
}

\section{Key Words}

Intensive care unit · Nondialytic therapy · End-of-life care

\begin{abstract}
It is frequently necessary to admit critically ill elderly patients to intensive care units (ICUs) due to their physiological impairments and co-morbidities. Several life-sustaining therapies such as mechanical ventilation are performed as necessary treatment in these ICUs. Sometimes renal replacement therapy (i.e. dialysis) is considered for elderly patients with complicating serious renal insufficiency. However, although the necessity for dialysis is recognized, some elderly patients may not benefit from this care because of their limited life expectancy. Until recently, life-sustaining support for critically ill elderly patients in Japan has been used routinely, regardless of the medical futility. The issue of providing better end-oflife care for elderly patients even in the ICU is now being raised frequently. We therefore wish to highlight the issue of end-of-life care and decision-making in the ICU, focusing on nondialytic therapy (NDT). The aim of this article was to assess whether NDT is an acceptable optional care for critically ill elderly patients with serious kidney diseases, even in the ICU. We hope our experiences may be helpful to physicians with an interest in decision-making and end-of-life care.

(C) 2014 S. Karger AG, Basel
\end{abstract}

\section{Introduction}

Like many other countries, the elderly population in Japan is increasing [1]. As a result, physicians need to diagnose and manage more elderly patients. It is frequently necessary to admit elderly patients with critical illnesses to intensive care units (ICUs) due to their physiological impairments and co-morbidities [2]. In that setting, several life-sustaining therapies such as mechanical ventilation are performed as a necessary treatment. Sometimes renal replacement therapy (i.e. dialysis) is considered for elderly patients with 
complicating serious renal insufficiency. However, although we recognize the necessity for dialysis, there are some elderly patients who may not benefit from this care as a result of their limited life expectancy [3]. As nephrologists, we would like to provide optional comfort care for such patients. In that context, we focused in this article on nondialytic therapy (NDT) as a better end-of-life care for patients [4]. The aim was to assess whether NDT is an acceptable optional care for critically ill elderly patients with serious kidney diseases, even in the ICU. The following is a case report of a patient with these characteristics.

\section{Case Presentation}

An 86-year-old man with chronic heart failure and atrial fibrillation was followed by a cardiologist as an outpatient and subsequently admitted to the ICU at our hospital because of septic shock associated with a urinary tract infection. His Charlson morbidity score was 7 [5]. After admission, he suffered from respiratory distress and required intubation for mechanical ventilation. Initially, his cardiologist, who was the attending doctor, preferred to use advanced care for the patient. However, the patient was unable to agree to this option because of his impaired level of consciousness and therefore the doctor obtained consent from the patient's family to initiate life-sustaining therapy. As a consequence of this intensive care that included antibiotic therapy and management of mechanical ventilation, the physical status of the patient recovered temporarily. However, on the 36th hospital day, the doctor confirmed a further reduction in his level of consciousness, and magnetic resonance imaging showed that a brain infarction had occurred. The patient's family was therefore informed of his poor prognosis. On the 48th hospital day, the patient developed acute panperitonitis caused by a gastrointestinal perforation. A surgeon proposed either an operation or conservative care for this condition to the family who subsequently selected conservative management.

After 49 hospital days, the patient's physical condition worsened, with the development of oliguria and progression of renal insufficiency. The attending doctor consulted us to discuss renal replacement therapy. After a careful diagnosis of the patient, we concluded that hemodialysis (HD) should be started immediately. However, his systolic blood pressure was barely maintained at approximately $80 \mathrm{~mm} \mathrm{Hg}$ by the administration of a continuous intravenous vasopressor. Moreover, sepsis became uncontrollable, associated with multiple organ failure, indicating that the patient was in the final stage of a life-limiting illness. A marked thrombocytopenia due to sepsis was also detected. As a consequence, it was considered that the insertion of the dialysis catheter for the initiation of HD may have resulted in uncontrollable bleeding. We therefore discussed with other cardiologists, nephrologists, and nurses in the ICU whether or not HD was a suitable care. We concluded that dialytic therapy would not be effective and that we could not practice HD safely because of the patient's poor condition. We also recognized that conservative or palliative care was more acceptable as end-of-life care for the patient.

Under such circumstances, we explained to the patient's family that HD would not contribute directly to the recovery of sepsis and that it may also be a further burden for him. In addition, we had also referred him to comfort or palliative care (i.e. NTD) as an optional endof-life treatment. However, the family became disturbed and withheld their decision from the first meeting, although one day later they agreed to NTD. We found that the preference for end-of-life care of the family changed considerably during this difficult period for the patient. 
Two days after obtaining consensus for this treatment, the patient died peacefully surrounded by his family in the ICU. Fortunately, the family confirmed that they were satisfied with our care.

\section{Discussion}

Until recently, life-sustaining support for critically ill elderly patients in Japan has been used routinely, regardless of the medical futility [6]. The issues regarding end-of-life care for elderly patients even in the ICU are currently being raised with greater frequency $[7,8]$. We therefore wish to highlight the issue of end-of-life care and decision-making in the ICU focusing on NDT.

Several studies have referred to NDT as an optional conservative management for patients with end-stage renal disease. Nephrologists need to manage life-threatening symptoms associated with uremia such as respiratory distress, pain, nausea, and sleep disturbances caused by medication used in NDT including opioids. Therefore, NDT can also be classified as a type of palliative care $[4,9]$.

The concept of NDT has been advanced as a result of respecting the patients' decisions regarding end-of-life care. Nevertheless, while the appropriateness of NDT for critically ill elderly patients in the ICU is debated, it is rarely practiced [10]. We suggest that the concept of NDT in the ICU should possibly be applied to the care of critically ill elderly patients with severe kidney diseases in order to provide better end-of-life care [11]. While NDT for elderly patients with stable end-stage renal disease is usually based on comprehensive discussions to obtain the informed consent of patients or their families regarding the will to live [3], it may be practiced under different situations for critically ill elderly patients with severe kidney diseases in the ICU setting.

First, we need to assess whether HD is merited in critically ill patients with a limited life expectancy. Second, under these circumstances, it can be difficult to confirm the patients' preference for care, especially end-of-life care, because of their impaired level of consciousness or the use of mechanical ventilation. Furthermore, it may be considerably more important that available guidelines are followed when practicing NDT.

If possible, we attempt to complete the process of shared decision-making on NDT by referring to the recommended guidelines [12]. As a consequence, we practice 'familycentered decision-making at the end of life', a concept that is preferred in the Japanese society [13]. We would like to emphasize that even after being resuscitated, both patients and their family have a second chance to consider or refine their preference for further care. In our opinion, we also need to avoid over-treatment that may prolong the suffering of patients.

Recently, patient-centered medicine has been widely reported [14]. We propose that NDT in ICUs based on sufficient shared decision-making may also be consistent with this concept. However, according to a survey, both physicians and patients in Japan are still reluctant to discuss issues of end-of-life care, although there exist guidelines supporting this [15-17]. We expect that education on end-of-life care for both health care providers and the public will be promoted [18].

Although we would like to discuss the preferable aspects of patient-centered medicine, it is also necessary to refer to the disadvantage of this care [19]. In a situation where patients are unable to state their preference for advanced care, as described in our case report, it is not possible to exclude the possibility that the treatment strategy may be influenced by the subjective assessments of health care providers. As a result, in some cases the decision- 
making may be contrary to the patients' wishes. In contrast, disease-based medicine can provide standardized evidence-based management for patients, although it is important to be aware of its limitations. In clinical practice, we observed that treatment focusing on disease control does not necessarily contribute to a better management of life-threatening symptoms such as respiratory distress or continuous pain. In cases of severely ill elderly patients with such symptoms and a limited life expectancy, we consider it necessary to prepare a palliative care plan as optional treatment.

In our opinion, it is necessary to maintain a balance between disease-based and patientcentered care, especially in severely ill elderly patients. Therefore, initially it is important to take sufficient time to assess the disease from a medical perspective with other health care providers such as doctors or nurses before withdrawing intensive care. Following this assessment, a plan of palliative care needs to be prepared based on the informed consent of the patients or their families.

Currently there is only limited evidence and established knowledge to support treatment decisions in patient-centered medicine. We therefore recommend that studies investigating the objective assessment of the decision-making process in patient-centered care should be conducted in the near future.

In conclusion, although the concept of patient-centered medicine has limitations, our results show that NDT may be worth considering for critically ill elderly patients with serious kidney diseases as an optional end-of-life care treatment, even in the ICU. We hope that our experiences are helpful to physicians who are interested in the practice of decisionmaking and end-of-life care.

\section{Acknowledgement}

This report was supported by the non-profit organization Epidemiological and Clinical Research Information Network (ECRIN).

\section{Disclosure Statement}

The authors have no relevant financial interests to declare.

\section{References}

1 Nakane J, Farevaag M: Elder care in Japan. Perspectives 2004;28:17-24.

2 Vosylius S, Sipylaite J, Ivaskevicius J: Determinants of outcome in elderly patients admitted to the intensive care unit. Age Ageing 2005;34:157-162.

-3 Berger JR, Hedayati SS: Renal replacement therapy in the elderly population. Clin J Am Soc Nephrol 2012;7:1039-1046.

4 Jassal SV, Kelman EE, Watson D: Non-dialysis care: an important component of care for elderly individuals with advanced stages of chronic kidney disease. Nephron Clin Pract 2011;119(suppl 1):c5-c9.

5 Charlson ME, Pompei P, Ales KL, MacKenzie CR: A new method of classifying prognostic comorbidity in longitudinal studies: development and validation. J Chronic Dis 1987;40:373-383.

6 Aita K, Kai I: Physicians' psychosocial barriers to different modes of withdrawal of life support in critical care: a qualitative study in Japan. Soc Sci Med 2010;70:616-622.

7 Aita K: End-of-life care in emergency settings in the super-aged society: withholding CPR from frail elderly with severe ADL impairment (in Japanese). Nihon Rinsho 2013;71:1089-1094.

8 Conti M, Merlani P, Ricou B: Prognosis and quality of life of elderly patients after intensive care. Swiss Med Wkly 2012;142:w13671. 


\begin{tabular}{l|l}
\hline Case Rep Nephrol Urol 2014;4:126-130 \\
\hline DOI: $10.1159 / 000363733$ & $\begin{array}{l}\text { C 2014 S. Karger AG, Basel } \\
\text { www.karger.com/cru }\end{array}$ \\
\hline
\end{tabular}

Ishikawa and Sakamoto: Nondialytic Therapy for Elderly Patients in a Critical Care Setting

9 Alston H: Conservative care for end-stage kidney disease: joint medical conference with the Renal Association, British Geriatrics Society and Association for Palliative Medicine. Clin Med 2013;13:383-386.

10 Zoraster R, Vanholder R, Sever MS: Disaster management of chronic dialysis patients. Am J Disaster Med 2007;2:96-106.

11 Curtis JR, Vincent JL: Ethics and end-of-life care for adults in the intensive care unit. Lancet 2010;376:13471353.

12 Moss AH: Shared decision-making in dialysis: the new RPA/ASN guideline on appropriate initiation and withdrawal of treatment. Am J Kidney Dis 2001;37:1081-1091.

-13 Nakazawa K, Kizawa Y, Maeno T, Takayashiki A, Abe Y, Hamano J, Maeno T: Palliative care physicians' practices and attitudes regarding advance care planning in palliative care units in Japan: a nationwide survey. Am J Hosp Palliat Care 2013, E-pub ahead of print.

14 Bardes CL: Defining 'patient-centered medicine'. N Engl J Med 2012;366:782-783.

15 Akabayashi A, Slingsby BT, Kai I: Perspectives on advance directives in Japanese society: a population-based questionnaire survey. BMC Med Ethics 2003;4:E5.

16 Jensen HI, Ammentorp J, Ording H: Guidelines for withholding and withdrawing therapy in the ICU: impact on decision-making process and interdisciplinary collaboration. Heart Lung Vessel 2013:5:158-167.

$>17$ Truog RD, Campbell ML, Curtis JR, Haas CE, Luce JM, Rubenfeld GD, Rushton CH, Kaufman DC; American Academy of Critical Care Medicine: Recommendations for end-of-life care in the intensive care unit: a consensus statement by the American College [corrected] of Critical Care Medicine. Crit Care Med 2008;36:953-963.

18 Thompson BT, Cox PN, Antonelli M, Carlet JM, Cassell J, Hill NS, Hinds CJ, Pimentel JM, Reinhart K, Thijs LG American Thoracic Society; European Respiratory Society; European Society of Intensive Care Medicine; Society of Critical Care Medicine; Sociètè de Rèanimation de Langue Française: Challenges in end-of-life care in the ICU: statement of the 5th International Consensus Conference in Critical Care: Brussels, Belgium, April 2003: executive summary. Crit Care Med 2004;32:1781-1784.

19 Bowling CB, O’Hare AM: Managing older adults with CKD: individualized versus disease-based approaches. Am J Kidney Dis 2012;59:293-302. 